\title{
Gamlin, J. et al. (eds). (2020). Critical Medical Anthropology: Perspectives in and from Latin America. London: UCL Press.
}

\author{
ULIANA ESTEVES
}

UNIVERSIDADE FEDERAL DO RIO DE JANEIRO (UFRJ), RIO DE JANEIRO/RJ, BRASIL

HTTPS://ORCID.ORG/OOOO-OOOI-77IS-94I3

Desigualdades estruturais, violência, discriminação e ativismo. Estas são algumas das categorias abordadas na obra organizada por Jennie Gamlin, Sahra Gibbon, Paola M. Sesia e Lina Berrio, pesquisadoras situadas na Inglaterra (as duas primeiras) e no México (as duas seguintes). Tais categorias se desdobram em dez capítulos, os quais tratam de distintas questões em torno do processo saúde/ doença/cuidado. Em conjunto os textos evidenciam aquilo que seria a caraterística da Antropologia Médica Crítica na América Latina (AMC-AL), demarcada, no prefácio, por Eduardo Menéndez: a descrição de contextos de exclusão, degradação, racismo e agressão a que foram submetidos setores sociais e grupos étnicos na região.

Menéndez, argentino radicado no México, é uma importante referência para a AMC-AL e suas discussões aparecem como um fio condutor do livro. Os conceitos de autocuidado e modelo médico hegemônico servem como base de argumentação para diversos textos. Para o autor, ao evidenciar distintas formas de cuidado, a AMC-AL demonstra uma visão holística do processo saúde/doença/ cuidado. A perspectiva biomédica unilateral - e as dinâmicas de poder aí envolvidas - é questionada a partir dos saberes de grupos subalternizados e da criação e usos de critérios preventivos.

O livro é resultado de uma série de eventos realizados no México, no Brasil, na Inglaterra e em Portugal (coordenados pelas organizadoras da obra) nos quais pesquisadores da Argentina, do Brasil, do Equador, do México, da Inglaterra e dos Estados Unidos apresentaram seus trabalhos. Segundo as organizadoras, os encontros aprofundaram o olhar da teoria crítica latino-americana sobre as desigualdades na saúde, sendo este o primeiro livro a reunir, na língua inglesa, contextos etnográficos da América Latina e teorias da AMC. O esforço seria o de difundir as pesquisas de autores com quase ou nenhuma publicação neste idioma. Tal estratégia é justificada pela riqueza dos trabalhos realizados na região, por suas especificidades históricas de engajamento com a teoria crítica e pelo fato de que no mundo acadêmico etnocêntrico e anglófono as contribuições da ACM-AL são escassas, sendo ignorada a produção antropológica em espanhol. O leque temático não conseguiu incluir, contudo, a importante contribuição dos estudos da saúde das populações negras desenvolvidos no Brasil, no 
Equador e na Colômbia, como ressaltado pelas organizadoras que, também, afirmam estar em débito com a Região Andina e o Cone Sul da América Latina.

Ao longo da coletânea é notável a força do referencial teórico latino-americano no tratamento das questões; além de Menéndez, destaca-se a presença do antropólogo mexicano Guillermo Bonfil Batalha. As orientações teóricas-metodológicas se mantêm alertas para determinantes sociais e relações de poder em torno da saúde/doença/tratamento e para as respostas coletivas e individuais aos problemas. A criatividade na articulação metodológica é outra marca dos capítulos. O trabalho de campo se vale de descrição de trajetórias, mapeamento social, análise de mídia e de discurso público.

O livro é dividido em três seções temáticas. Os quatro capítulos que compõem a primeira parte - "Intercultural health: Critical approaches and current challenges" - abordam questões relativas ao ativismo e à intermedicalidade. No primeiro, Esther Jean Langdon e Eliana E. Diehl retomam processos de formação e consolidação do Grupo de Trabalho em Saúde Indígena da Associação Brasileira de Saúde Coletiva (ABRASCO). As autoras consideram que os engajamentos críticos dessa rede interdisciplinar de pesquisadores contribuiriam para as discussões de uma abordagem crítica latino-americana. Seus membros articulam a pesquisa com a participação em fóruns públicos de formulação e avaliação de políticas de saúde.

Para examinar essa articulação, Langdon e Diehl abordam, especificamente, o Núcleo de Estudos sobre Saúde e Saberes Indígenas (NESSI) e suas investigações sobre os cuidados entre os Kaingáng de Santa Catarina e os distintos modos de participação indígena no sistema de saúde. O texto sublinha, ainda, que a postura crítica da antropologia da saúde no Brasil acarreta uma rejeição da antropologia médica como rótulo, entendendo que ela subordinaria o conhecimento antropológico ao empirismo biológico e psicológico da ciência médica na compreensão do sofrimento humano.

O capítulo de Jennie Gamlin e Lina Berrio, por sua vez, busca extrair as contribuições da etnografia colaborativa e de longo prazo com as comunidades indígenas para a teoria crítica na antropologia médica. A agência dessas populações na saúde e na pesquisa seriam fundamentais para uma produção teórica sobre medicina e saúde que emerge dos mundos indígenas. Ao discutir as experiências de parto de Sukulima e Juana, mulheres indígenas acompanhadas por projetos comunitários de saúde da mulher no México, as autoras entendem que as colaborações entre pesquisa e ativismo em torno da mortalidade materna estão coproduzindo uma teoria antropológica crítica anticolonial.

Partindo de uma perspectiva da antropologia das emoções, Frida Jacobo Herrera e David Orr apresentam um estudo comparativo sobre a experiência do susto, conhecido também como "doença do medo" ou "perda da alma", no México e no Peru. As dimensões emocionais da experiência do medo ofereceriam uma visão crítica sobre as vulnerabilidades experimentadas por grupos sociais específicos. O esforço teórico dos autores recai sobre a análise dos imbricamentos entre a produção sociocultural de experiências emocionais e as estruturas socioeconômicas, a partir da observação de como as comunidades podem vincular condições como susto ao sofrimento social. Os medos dessas comunidades responderiam a ameaças específicas - como a violência -, mas também seriam moldados por marcadores como gênero, classe e idade. 
O capítulo escrito por Rebecca Irons, fechando a primeira seção da coletânea, questiona a monossemia do entendimento biomédico sobre dois medicamentos que podem ser tomados após a relação sexual desprotegida - a pílula anticoncepcional de emergência e o misoprostol (uma "pílula abortiva") - a partir do uso feito por mulheres de baixa renda no Peru. A percepção e o uso de pílulas pós-coito estariam intimamente relacionados aos conceitos locais de tempo no desenvolvimento fetal. As diferentes medidas temporais mobilizadas pelas mulheres sugerem que a pílula pós-coito existe em "realidades múltiplas" nesse contexto. As realidades conflitantes entre a experiência das mulheres e a das principais instituições controladoras da política e da opinião pública aprofundariam a precariedade da saúde de mulheres em posições vulneráveis.

Os fluxos de pessoas por espaços fronteiriços e de saberes por entre redes de conhecimento são discutidos na segunda parte do livro - "Globalisation and contemporary challenges of border spaces and biologised difference" - composto por três capítulos. Olga Lidia Olivas Hernández analisa trajetórias de homens migrantes na região de fronteira entre os Estados Unidos e o México. O texto examina a sobreposição entre trajetórias de migração e práticas e significados do uso de drogas, investigando como a experiência de migrar afeta a saúde dos sujeitos. A autora identifica diferentes interpretações para o uso de drogas: doença, hábito, vício e, ainda, estratégia de autocuidado no enfrentamento das dificuldades vivenciadas em condições de precariedade. Tal uso também pode ser entendido como uma consequência da violência estrutural exercida pelo sistema de imigração norte-americano.

O capítulo seguinte, assinado por Rubén Muñoz Martínez, Carmen Fernández Casanueva, Sonia Morales Miranda e Kimberly C. Brouwer é apresentado como o primeiro estudo focado na fronteira do México com a Guatemala a analisar as condições socioeconômicas, políticas e culturais implicadas na exposição ao HIV por homens migrantes indocumentados que realizam trabalhos sexuais. Os autores fazem um mapeamento social dos espaços percorridos por esses sujeitos com o interesse de analisar a estigmatização e discriminação por eles vividas. Assim, elucidam processos de vulnerabilização social ao HIV de migrantes masculinos em um contexto de fronteira.

No capítulo que encerra a segunda seção, Melania Calestani e Laura Montesi analisam, a partir de uma abordagem comparativa, as representações sociais da diabetes no México e das minorias étnicas na medicina de transplante no Reino Unido. As autoras consideram que a reinvenção das categorias "raça" e "etnia" pela ciência apontaria para como o reforço étnico-racial pode contribuir com o aprofundamento de desigualdades racializadas em sociedades estratificadas. Calestani e Montesi tomam como aporte teórico discussões da antropologia da epigenética e, principalmente, da epidemiologia crítica para analisar como "influências sociais" podem se corporificar. Para as autoras, esta abordagem não nega as diferenças étnico-raciais nos padrões de doença, contudo as compreende como "resultados encarnados de caminhos de poder”, caracterizadas por uma somatização das tensões raciais. À medida que as instituições da ciência examinam seus corpos, os próprios sujeitos também dão sentidos à diabetes e à doação de órgãos.

A última parte do livro, com três capítulos, é intitulada "Political economy and judicialisation". Rosa María Osorio Carranza discute a expansão de um tipo específico de sistema de saúde privado que vem se consolidando no México. Tal sistema se caracteriza pela alocação de consultórios contíguos a 
farmácias. Promovido pela indústria farmacêutica, o surgimento dessas clínicas gerais privadas é enquadrado no contexto de políticas públicas para a privatização dos serviços de saúde no país. Carranza considera que este modelo ratifica um processo de farmacologização que incrementa o uso de medicamentos. O olhar para este processo considera, ainda, as motivaçóes dos diversos atores envolvidos no sistema, como os usuários e suas escolhas.

Paola M. Sesia descreve o caso emblemático de violação do direito à assistência durante o parto de Irma López Aurélio, indígena de Oaxaca, no México. O texto apresenta uma análise de como a violência obstétrica emerge enquanto categoria mobilizada por organizações litigantes no processo de judicialização da violação de direitos humanos na saúde materna sofrida por Irma. Sesia considera este enquadramento como um terreno fértil para investigações desde uma perspectiva da AMC-AL. "Violência obstétrica” se revela como uma categoria semântica, constituinte de um novo marco jurídico na defesa dos direitos humanos das gestantes; e, também, epistêmica, na medida em que define um campo social de atuação médica, apresentando uma crítica à obstetrícia hegemônica.

No último capítulo da obra, Waleska Aureliano e Sahra Gibbon analisam o processo de judicialização no caso de doenças raras no Brasil. As autoras mostram as nuances dos "complexos emaranhados" entre o tribunal e a clínica, descrevendo, com delicadeza, os modos como as categorias "vida" e "valor" são mobilizadas e contestadas nos terrenos onde a judicialização se desenvolve no país. Aureliano e Gibbon discutem como, nesse contexto, são gerados tipos particulares de subjetividades políticas ambíguas. A noção de economias afetivas também é empregada para examinar como reivindicações múltiplas, em especial dos pacientes e seus familiares, sobre o valor ou preço da vida são mobilizadas na judicialização de medicamentos de alto custo para doenças raras no Brasil.

O posfácio é de autoria de Claudia Fonseca, antropóloga norte-americana radicada no Brasil, importante referência, em especial, nos estudos de gênero, família, adoção e ciências. Além de alinhavar as principais questões levantadas na obra, mormente a alocação da biomedicina como um dentre os variados sistemas possíveis de cuidados, e de sublinhar a pertinência do trabalho etnográfico, Fonseca aponta para desdobramentos necessários nas investigações da AMC na América Latina. O primeiro ponto destacado é o de pensar em como identificar e alistar, entre os agentes da biomedicina, aliados críticos, profissionais que, ao vivenciarem as ambivalências de suas práticas, possam estar abertos ao diálogo e às alterações criativas nos próprios saberes e práticas. $\mathrm{O}$ segundo é incluir na perspectiva antropológica crítica a influência de várias agências internacionais. Desta forma, chama atenção para como os esforços humanitários de organizações internacionais por vezes estão associados a intervenções militares e bloqueios econômicos, levantando questões sobre motivações e efeitos das ações. Por fim, destaca como os problemas abordados na obra não são simples, por isso defende que o engajamento dos pesquisadores deva vir apoiado pelo envolvimento dos pacientes. Esse envolvimento ajudaria, segundo Fonseca, na formulação de alternativas novas e mais eficazes no combate às desigualdades incorporadas que afligem o mundo contemporâneo.

Apesar do notável esforço de inserir a teoria latino-americana em um mercado anglófono, a publicação da coletânea apenas em inglês decerto impõe limites para o acesso à leitura na região. Contudo, a obra é uma necessária contribuição para a antropologia e se torna referência importante nos estu- 
dos de saúde/doença/cuidado e ativismo. O esforço etnográfico de descrição multiescalar de processos políticos e econômicos revela como esses não servem apenas como pano de fundo ou de contextualização das situações, mas antes, como eles são corporificados, produzem relações e instauram resistências. O comprometimento político dos autores também é uma marca importante da obra e da própria AMC-AL. A potência dos engajamentos é reverberada na produção teórica e no desenvolvimento de etnografias multissituadas que explicitam e contribuem com os diversos espaços de lutas por direitos. A obra é, pois, um chamado ao diálogo e um convite a um mergulho na teoria social latino-americana.

Uliana Esteves é Doutora em Antropologia Social pelo Programa de Pós-Graduação em Antropologia Social do Museu Nacional/Universidade Federal do Rio de Janeiro (PPGAS/MN/UFRJ).

RECEBIDO: 01/02/2021

APROVADO: $03 / 03 / 2021$ 